\title{
Thermodynamics of Biomass-Based Solid Fuels
}

\author{
Michael Ioelovich* \\ Celdesigner Ltd, Rehovot 7670504, Israel \\ Submission: August 14, 2018; Published: October 09, 2018 \\ *Corresponding author: Michael Ioelovich, Celdesigner Ltd, Israel, Email: ioelovichm@gmail.com
}

\section{Abstract}

In this paper, solid fuels made of plant biomass were studied as an alternative to fossil coals. For this purpose, experimental and calculation methods were applied to determine the standard change of internal energy or specific energy of combustion $\left(\Delta_{c} U_{i}^{\circ}\right)$ standard enthalpies of combustion $\left(\Delta_{c} H_{i}^{o}\right)$ and formation $\left(\Delta_{f} H_{i}^{o}\right)$ for individaual components of plant biomass (lignin, cellulose, hemicelluloses, extractives, etc.), as well as of some additives of solid biofuels. The experiments were carried out using an oxygen bomb calorimeter, whereas calculations were performed by the equation:

$$
\Delta_{c} U_{i}^{o}=E(c+0.295 h-0.42 o),
$$

where $\mathrm{E}=-413 \mathrm{~kJ} / \mathrm{mol}, \mathrm{c}, \mathrm{h}$ and o is number of atoms $\mathrm{C}, \mathrm{H}$ and $\mathrm{O}$, respectively, in molecule of organic substance or in repeat unit of polymer. Using the results obtained for individual components, the standard thermodynamic characteristics (TDC), $Y^{o}$, of various biomasses and their based fuels were found according to additivity rule, as follows: $Y^{o}=\Sigma w_{i} Y^{\circ}{ }_{i}$, where $w_{i}$ is weight part of the component in the biofuel. The results revealed that calculated TDC the solid fuels were close to experimentally obtained characteristics. The obtained data evidence on adequacy of the additivity rule to evaluate the TDC of solid biofuels. It has been also found that fuel pellets consisting of plant biomass and additive of plastic binders are the most promising solid fuels, since they provide a higher value of thermal energy and increased energy density than the biomass only.

Keywords: Plant biomass, Biofuel; Cellulose; Hemicelluloses; Lignin; Extractives; Thermodynamic characteristics; Calorimetry; Calculation

\section{Introduction}

Currently, the main solid fuels are fossil coals, which provides $28-30 \%$ of annual energy consumption in the world, about 160 $180 \mathrm{EJ}$ [1]. To generate such energy, more than 6 billion tons of coal are burned each year. However, this fossil source of energy is not reproduced in nature, and therefore its reserves are permanently depleted. Besides, the burning of coals is accompanied by emission of greenhouse gas - carbon dioxide, in the huge volume of $1700-1800 \mathrm{~m}^{3}$ from each ton, which can exacerbate the problem of global warming [2].

An alternative to coal can be a solid fuel based on plant biomass, which in contrast to this fossil fuel, is reproduced in nature. The term "biomass" means here a variety of plant materials, as well as their residues and wastes [3]. Diverse types of biomass can be used to produce of solid fuels such as softand hardwood; herbaceous plants (e.g. Miscanthus, Switchgrass, Bermuda grass, etc.); forest residues (e.g. sawdust, twigs, shrubs, etc.); residues of agricultural plants (e.g. stalks, husks, cobs, etc.); residues, waste and trash of textile, pulp, paper, cardboard and plants, as well as algae biomass, etc. Total amount of available biomass aimed especially for energy production is estimated at 8-10 billion tons [4].

As is known, all constituents of biomass are photosynthesized in chlorophyll pigment of plant leaves from carbon dioxide and water, absorbing red and blue-violet sunlight $[5,6]$. In fact, plant biomass can be considered an accumulator of solar energy captured during photosynthesis. To generate the heat energy, the biomass is burned, resulting in the release of accumulated solar energy. A specific feature of the biomass that it is neutral for emission of carbon dioxide, since its combustion produces the same amount of this greenhouse gas as it was absorbed from the atmosphere during photosynthesis.

However, the plant biomass is a heterogeneous material having low bulk density, which consists of pieces of different shapes, sizes and compositions. These negative features lead to deterioration in fuel properties - unstable calorific value, low density of thermal energy and insufficient combustion efficiency [7]. To increase the low energetic density, the loose biomass should be converted into dense pellets. Nevertheless, even after compaction, other negative biomass characteristics remain, such as low calorific value and sensitivity of the solid fuel to water absorption. A promising way to improve the fuel features of biomass is the use of plastic binders in the pelletization process [8]. As is known, large amounts of plastic waste about 250-300 million tons are thrown out annually and pollute the environment [9]. After separation of PET bottles from plastic debris, the main fraction of the plastic waste consists of polyolefins, which can be used as additive to biomass for co-firing. 
The use of biomass and its mixtures with polymer binders for production of solid fuels requires knowledge of standard specific energy of combustion $\left(\Delta_{c} U^{o}\right)$ and other Thermodynamic Characteristics (TDC). Numerous attempts have been performed to determine the $\Delta_{c} U^{o}$ values for certain types of biomass and synthetic polymers using the precise experimental method, namely a combustion of sample in a bomb calorimeter [10-13], as well as various calculation methods [13-16]. However, the calorimetric measurements are lengthy and requires multiple repetitions to obtain a reliable result; besides bomb calorimeter is a complex, expensive and not always available device. On the other hand, to calculate the $\Delta_{c} U^{o}$ value for each biomass type, its own equation has been proposed [13-15]. Since an unlimited number of different types of biomass and its based compositions exists, an unlimited number of experiments or calculations are required to determine the TDC of various solid fuels, which is impossible to realize.

For this reason, another approach should be used. As is known, any plant biomass contains cellulose, hemicelluloses, lignin, extractives and small amounts of some other substances. Besides, mixed solid fuel can contain also plastic additive. Thus, to find the TDC of solid fuels made of biomass or its mixture with plastics, it is sufficient to determine the TDC for limited number of individual components and their content in the sample and then use the additivity rule.

Although some TDC of individual components of plant biomass has been studied by various researchers, the obtained results were insufficiently reliable since they were varied over a wide range. For example, a considerable variation in the $\Delta_{c} U^{o}$ values for lignin samples, from 20 to $29 \mathrm{~kJ} / \mathrm{g}$ was observed [15,17,18], whereas the variation in specific energy of combustion for cellulose and hemicellulose samples was from 16.9 to $18.6 \mathrm{~kJ} / \mathrm{g}$ [10,15,17-19].

The purpose of this study was an accurate determination of standard thermodynamic characteristics of individual components of biomass, as well as of some plastic binders, in order to use the obtained results to evaluate the TDC of solid biofuels by means of additivity rule.

\section{Experimental}

\section{Samples}

Various types of biomass were used such as chips of spruce, pine and poplar, corn, wheat straw, switchgrass and bagasse of sugarcane, as well as waste paper and cardboard. The biomass samples were cut, knife-milled and screened through a sieve to obtain the fraction of $1-2 \mathrm{~mm}$.

The samples of bleached chemical grade Cotton Cellulose (COC) and Kraft Pulp (KRP) were used. Besides cellulose was isolated from Bagasse (BAC), Wheat Straw (WSC), Corn Stalks (CSC) and Switchgrass (SGC) by a two-stage pulping using dilute nitric acid and alkali with additional bleaching [20]. The cellulose samples were additionally purified by extraction with organic solvents, chelating agent (EDTA), boiling $2 \% \mathrm{NaOH}$ and boiling water to neutral $\mathrm{pH}$; then samples were rinsed with deionized water, ethanol and dried at $380 \mathrm{~K}$ to constant weight. The main characteristics of the samples (crystallinity index CrI, degree of polymerization DP, content of ash and $\alpha$-cellulose) are shown in the Table 1.

Table 1: Characteristics of cellulose samples.

\begin{tabular}{|c|c|c|c|c|}
\hline Sample & CrI & DP & Ash, \% & $\alpha$-cellulose, \% \\
\hline COC & 0.67 & 2700 & 0.1 & $>99$ \\
\hline KRP & 0.62 & 1200 & 0.2 & 98 \\
\hline BGC & 0.54 & 720 & 0,2 & 97 \\
\hline WSC & 0.53 & 650 & 0.2 & 97 \\
\hline CSC & 0.52 & 630 & 0.3 & 97 \\
\hline SGC & 0.52 & 610 & 0.3 & 97 \\
\hline
\end{tabular}

Samples of starch, pentosans, hexosans, Abietic Resin Acid (ABA) and Triglycerides of Stearic (TGS), palmitic (TGP), were supplied from Sigama-Aldrich. Klason lignin was isolated from various biomasses using standard TAPPI method T222. Powdered polyolefins were supplied from Ineos Olefins and Sigma-Aldrich.

\section{Pelletization}

The ground biomass was blended with powdered polyolefin, and the mixture was compacted under pressure $50 \mathrm{MPa}$ at temperature of $445-450 \mathrm{~K}$ for $1-2 \mathrm{~min}$. For comparison, the pelletized biomass was also prepared under the same conditions.

\section{Characterization of samples}

Chemical composition of biomass samples was studied by standard NREL methods [21]: LAP-001 (total solids), LAP-002 (cellulose and hemicelluloses), LAP-003 (lignin), LAP-005 (ash) and LAP-010 (extractives). Bulk density was tested by standard method ASTM E-873. Average degree of polymerization (DP) of cellulose was measured by the viscosity method using diluted cellulose solutions in Cadoxen [22]. Index of cellulose crystallinity (CrI) was estimated using Jayme and Knolle method [23].

\section{Combustion calorimetry}

Combustion of samples in pelletized form (cca. 1g) was carried out in a bomb calorimeter Parr-1341 at oxygen pressure of $3 \mathrm{MPa}$ with $1 \mathrm{ml}$ of added deionized water. The temperature and its rise $(\Delta T)$ were measured with accuracy $\pm 0.001 \mathrm{~K}$. The value of energy equivalent of the calorimetric system (C) was determined by combustion of standard benzoic acid. The correction of internal energy change $\left(\Delta_{c} U\right)$ for ignition $\left(\mathrm{e}_{1}\right)$, as well as for formation and dissolution of nitric acid $\left(\mathrm{e}_{2}\right)$ were taken into account:

$$
\Delta_{c} U=M\left(C \Delta T-e_{1}-e_{2}\right) / m
$$

where $\mathrm{m}$ is true mass of sample, $\mathrm{M}$ is molecular mass of substance or repeat unit of polymer.

To obtain the standard value of specific energy of combustion $\left(\Delta_{c} H^{o}\right)$ the Washburn's correction was introduced. When the standard enthalpy of combustion $\left(\Delta_{c} H^{o}\right)$ is calculated, the correction was introduced for change in number of moles of gases before and after combustion. The standard enthalpy of formation $\left(\Delta_{f} H^{o}\right)$ was calculated by the known equation: 


\section{Academic Journal of Polymer science}

$\left(\Delta_{c} H_{i}\right)\left(\Delta_{f} H^{o}\right) \quad \Delta_{f} H^{o}=n\left(\mathrm{CO}_{2}\right) \Delta_{f} H^{o}\left(\mathrm{CO}_{2}, g\right)+n\left(\mathrm{H}_{2} \mathrm{O}\right) \Delta_{f} H^{o}\left(\mathrm{H}_{2} \mathrm{O}, l\right)-\Delta_{c} H^{o}$

where $\mathrm{n}\left(\mathrm{CO}_{2}\right)$ and $\mathrm{n}\left(\mathrm{H}_{2} \mathrm{O}\right)$ are number of moles of $\mathrm{CO}_{2}$ and $\mathrm{H}_{2} \mathrm{O}$ in combustion reaction; $\Delta_{f} H^{o}\left(\mathrm{CO}_{2}, \mathrm{~g}\right)=-393.51 \mathrm{~kJ} / \mathrm{mol}$ and $\Delta_{f} H^{\circ}$ $\left(\mathrm{H}_{2} \mathrm{O}, \mathrm{l}\right)=-285.83 \mathrm{~kJ} / \mathrm{mol}$ are standard enthalpies of formation of carbon dioxide and liquid water.
For each sample three experiments were performed to obtain the reliable TDC.

\section{Results and Discussion}

The results of calorimetric determination of standard thermodynamic characteristics of individual components of plant biomass are shown in Tables 2-5.

Table 2: TDC of cellulose samples.

\begin{tabular}{|c|c|c|c|}
\hline Sample & $-_{\mathbf{A}} \mathbf{U}^{\mathbf{0}}, \mathbf{k J} / \mathbf{m o l}$ & $-\ddot{\mathbf{A}}_{\mathbf{c}} \mathbf{U}^{\mathbf{0}} \mathbf{~ k J} / \mathbf{m o l}$ & $-\ddot{\mathbf{A}}_{\mathbf{f}} \mathbf{H}^{\mathbf{0}}, \mathbf{k J} / \mathbf{m o l}$ \\
\hline COC & 2827.5 & 2827.5 & 962.5 \\
\hline KRP & 2829.6 & 2829.6 & 960.6 \\
\hline BGC & 2832.1 & 2832.1 & 958.1 \\
\hline WSC & 2833 & 2833 & 957.2 \\
\hline CSC & 2832.6 & 2832.6 & 957.6 \\
\hline SGC & 2832 & 2832 & 958.2 \\
\hline Average: & $2831.2 \pm 2.2$ & $2831.2 \pm 2.2$ & $959.0 \pm 2.1$ \\
\hline
\end{tabular}

Table 3: TDC of non-cellulose carbohydrates.

\begin{tabular}{|c|c|c|c|}
\hline Sample & $-\ddot{\mathbf{A}}_{\mathbf{c}} \mathbf{U}^{\mathbf{0}}, \mathbf{k J} / \mathbf{m o l}$ & $-\ddot{\mathbf{A}}_{\mathbf{c}} \mathbf{U}^{\mathbf{0}}, \mathbf{k J} / \mathbf{m o l}$ & $-\ddot{\mathbf{A}}_{\mathbf{r}} \mathbf{H}^{\mathbf{0}}, \mathbf{k J} / \mathbf{m o l}$ \\
\hline Starch & $2833.1 \pm 2.1$ & $2833.1 \pm 2.1$ & $957.1 \pm 2.1$ \\
\hline Hexosans & $2833.6 \pm 2.4$ & $2833.6 \pm 2.4$ & $956.6 \pm 2.4$ \\
\hline Pentosans & $2348.0 \pm 2.3$ & $2348.0 \pm 2.3$ & $762.9 \pm 2.3$ \\
\hline
\end{tabular}

Table 4: TDC of lignin samples.

\begin{tabular}{|c|c|c|c|}
\hline Sample & $-\ddot{\mathbf{A}}_{\mathrm{c}} \mathbf{U}^{0}, \mathrm{~kJ} / \mathrm{mol}$ & $-\ddot{\mathbf{A}}_{\mathrm{c}} \mathbf{U}^{0}, \mathrm{~kJ} / \mathrm{mol}$ & $-\ddot{\mathbf{A}}_{\mathrm{f}} \mathbf{H}^{0}, \mathrm{~kJ} / \mathrm{mol}$ \\
\hline Lignin of spruce & 5196.1 & 5198.3 & 559.5 \\
\hline Lignin of pine & 5198.3 & 5200.5 & 557.5 \\
\hline Average: & $5197.2 \pm 2.1$ & $5199.4 \pm 2.1$ & $558.5 \pm 2.1$ \\
\hline Lignin of poplar & 5050 & 5051.7 & 626.3 \\
\hline Lignin of bagasse & 5051.3 & 5053 & 625 \\
\hline Lignin of switchgrass & 5048.8 & 5050.5 & 627.5 \\
\hline Lignin of straw & 5050.4 & 5052 & 626 \\
\hline Lignin of corn stalks & 5051.7 & 5053.4 & 624.6 \\
\hline Average: & $5050.4 \pm 2.2$ & $5052.1 \pm 2.2$ & $625.9 \pm 2.2$ \\
\hline
\end{tabular}

Table 5: TDC of components of extractives.

\begin{tabular}{|c|c|c|c|c|}
\hline Sample & $\mathbf{M}$ & $-\ddot{\mathbf{A}}_{\mathbf{c}} \mathbf{U}^{\mathbf{0}}, \mathbf{k J} / \mathbf{m o l}$ & $-\ddot{\mathbf{A}}_{\mathbf{c}} \mathbf{U}^{\mathbf{o}}, \mathbf{k J} / \mathbf{m o l}$ & $-\ddot{\mathbf{A}}_{\mathbf{f}} \mathbf{H}^{\mathbf{0}}, \mathbf{k J} / \mathbf{m o l}$ \\
\hline ABA & 302 & $11564.4 \pm 2.0$ & $11580.1 \pm 2.1$ & $577.6 \pm 2.1$ \\
\hline TGP & 806 & $31988.4 \pm 3.1$ & $32041.7 \pm 3.4$ & $2033 \pm 3.4$ \\
\hline TGS & 890 & $35925.3 \pm 3.7$ & $35986.0 \pm 4.0$ & $2164.7 \pm 4.0$ \\
\hline
\end{tabular}

As can be seen from Tables 2 and Table 3, when determine the TDC of carbohydrates the relative divergence between combustion energies or enthalpies was small, about $\pm 0.1 \%$. The obtained average values of TDC were in the range given in literature $[10,16,19,24]$.

The study of lignin samples has shown (Table 4) that specific energy of combustion for lignins of softwood were higher than the corresponding values for lignins isolated from hardwood (Lignin-S) and herbaceous plants (Lignin-H). The study of components of extractive substances (resin acids, e.g. ABA, and various lipids) has shown that standard energy and enthalpy of combustion was proportional to molecular mass of these substances (Table 5). 
Table 6: TDC of some polyolefins.

\begin{tabular}{|c|c|c|c|}
\hline Sample & $-\ddot{\mathbf{A}}_{\mathbf{c}} \mathbf{U}^{\mathbf{0}}, \mathbf{k J} / \mathbf{m o l}$ & $-\ddot{\mathbf{A}}_{\mathbf{c}} \mathbf{U}^{\mathbf{o}}, \mathbf{k J} / \mathbf{m o l}$ & $-\ddot{\mathbf{A}}_{\mathbf{f}} \mathbf{H}^{\mathbf{0}}, \mathbf{k J} / \mathbf{m o l}$ \\
\hline PEHD & $658.0 \pm 1.0$ & $659.2 \pm 1.2$ & $20.1 \pm 1.2$ \\
\hline PELD & $657.8 \pm 1.1$ & $659.0 \pm 1.1$ & $20.3 \pm 1.1$ \\
\hline PP & $1973.4 \pm 1.3$ & $1977.1 \pm 1.1$ & $61.0 \pm 1.1$ \\
\hline PS & $4273.8 \pm 1.5$ & $4278.8 \pm 1.6$ & $12.6 \pm 1.6$ \\
\hline
\end{tabular}

The determined TDC of some polyolefins (Table 6) are of biomass, components of extractives, as well as some plastics confirmed by literature data $[13,25]$.

In addition to experimental, there are also quite accurate cal(Tables 7-9). For this purpose, the following equations can be used [26]: culating methods to determine the TDC of individual biopolymers

Table 7: Experimental (exp) and calculated (calc) TDC of biopolymers in kJ/mol.

\begin{tabular}{|c|c|c|c|c|c|}
\hline Sample & Formula & $\mathbf{M}$ & $-\ddot{\mathbf{A}}_{\mathbf{c}} \mathbf{U}^{\mathbf{0}}$ exp (calc) & $-\ddot{\mathbf{A}}_{\mathbf{c}} \mathbf{U}^{\mathbf{0}} \exp$ (calc) & $-\ddot{\mathbf{A}}_{\mathbf{f}} \mathbf{H}^{\mathbf{0}} \exp$ (calc) \\
\hline Cellulose & $-\mathrm{C}_{6} \mathrm{H}_{10} \mathrm{O}_{5}{ }^{-}$ & 162 & $2831.2(2829.1)$ & $2831.2(2829.1)$ & $959.0(961.1)$ \\
\hline Starch & $-\mathrm{C}_{6} \mathrm{H}_{10} \mathrm{O}_{5}{ }^{-}$ & 162 & $2833.1(2829.1)$ & $1833.1(2829.1)$ & $957.1(961.1)$ \\
\hline Hexosans & $-\mathrm{C}_{6} \mathrm{H}_{10} \mathrm{O}_{5}{ }^{-}$ & 162 & $2833.6(2829.1)$ & $2833.6(2829.1)$ & $956.6(961.1)$ \\
\hline Pentosans & $-\mathrm{C}_{5} \mathrm{H}_{8} \mathrm{O}_{4^{-}}$ & 132 & $2348.0(2345.8)$ & $2348.0(2345.8)$ & $762.9(765.0)$ \\
\hline Lignin-S & $-\mathrm{C}_{11} \mathrm{H}_{10} \mathrm{O}_{3.2^{-}}$ & 193 & $5197.2(5206.3)$ & $5199.4(5208.5)$ & $558.5(549.4)$ \\
\hline Lignin-H & $-\mathrm{C}_{10.8} \mathrm{H}_{10} \mathrm{O}_{3.6^{-}}$ & 197 & $5050.4(5054.3)$ & $5052.1(5056.0)$ & $625.9(622.0)$ \\
\hline
\end{tabular}

Table 8: Experimental (exp) and calculated (calc) TDC of components of extractives in kJ/mol.

\begin{tabular}{|c|c|c|c|c|c|}
\hline Sample & Formula & $\mathbf{M}$ & $-\ddot{\mathbf{A}}_{\mathbf{c}} \mathbf{U}^{\mathbf{0}} \exp$ (calc) & $-\ddot{\mathbf{A}}_{\mathbf{c}} \mathbf{U}^{\mathbf{0}} \exp$ (calc) & $-\ddot{\mathbf{A}}_{\mathbf{r}} \mathbf{H}^{\mathbf{0}} \exp (\mathbf{c a l c})$ \\
\hline $\mathrm{ABA}$ & $\mathrm{C}_{20} \mathrm{H}_{30} \mathrm{O}_{2}$ & 302 & $11564.4(11568.1)$ & $11580.1(11584.2)$ & $577.6(573.5)$ \\
\hline $\mathrm{TGP}$ & $\mathrm{C}_{51} \mathrm{H}_{98} \mathrm{O}_{6}$ & 806 & $31988.4(31962.1)$ & $32041.7(32015.4)$ & $2033.0(2059.3)$ \\
\hline TGS & $\mathrm{C}_{57} \mathrm{H}_{110} \mathrm{O}_{6}$ & 890 & $35925.3(35902.1)$ & $35986.0(35962.8)$ & $2164.7(2187.9)$ \\
\hline
\end{tabular}

Table 9: Experimental (exp) and calculated (calc) TDC of polyolefins in $\mathrm{kJ} / \mathrm{mol}$.

\begin{tabular}{|c|c|c|c|c|c|}
\hline Sample & Formula & M & $-\ddot{\mathbf{A}}_{\mathbf{c}} \mathbf{U}^{\mathbf{0}} \exp$ (calc) & $-\ddot{\mathbf{A}}_{\mathbf{c}} \mathbf{U}^{\mathbf{0}} \exp$ (calc) & $-\ddot{\mathbf{A}}_{\mathbf{f}} \mathbf{H}^{\mathbf{0}} \exp (\mathbf{c a l c})$ \\
\hline PEHD & $-\mathrm{CH}_{2}{ }^{-}$ & 14 & $658.0(656.7)$ & $659.2(658.0)$ & $20.1(21.3)$ \\
\hline PELD & $-\mathrm{CH}_{2}{ }^{-}$ & 14 & $657.8(656.7)$ & $659.0(658.0)$ & $20.3(21.3)$ \\
\hline PP & $-\mathrm{C}_{3} \mathrm{H}_{6}-$ & 42 & $1973.4(1970.0)$ & $1977.1(1973.7)$ & $61.0(64.3)$ \\
\hline PS & $-\mathrm{C}_{8} \mathrm{H}_{8}-$ & 104 & $4273.8(4278.7)$ & $4278.8(4282.4)$ & $12.6(9.0)$ \\
\hline
\end{tabular}
$\Delta_{c} U^{o}=E(c+0.295 h-0.42 o)$
(3) repeat unit of polymer. $M C=\left[n\left(\mathrm{CO}_{2}-n\left(\mathrm{O}_{2}\right)\right] R T^{\circ}\right.$ is correction for
$\Delta_{c} H^{o}=E(c+0.295 h-0.42 o)+M C$ change of moles $\mathrm{CO}_{2}$ and $\mathrm{O}_{2}$ during combustion process, $T^{\circ}=298$ $\mathrm{K}$ is standard temperature.

where $\mathrm{E}=-413 \mathrm{~kJ} / \mathrm{mol} ; c, h$ and $O$ are number of atoms

$C, H$ and $O$ respectively in molecule of organic substance or in

The standard enthalpy of formation was calculated by equation (2)

Table 10: Experimental (exp) and calculated (calc) TDC of biopolymers in kJ/g.

\begin{tabular}{|c|c|c|c|c|c|}
\hline Sample & Formula & M & $-\ddot{\mathbf{A}}_{\mathbf{c}} \mathbf{U}^{\mathbf{0}} \exp$ (calc) & $-\ddot{\mathbf{A}}_{\mathbf{c}} \mathbf{U}^{\mathbf{0}} \exp$ (calc) & $-\ddot{\mathbf{A}}_{\mathbf{f}} \mathbf{H}^{\mathbf{0}} \exp$ (calc) \\
\hline Cellulose & $-\mathrm{C}_{6} \mathrm{H}_{10} \mathrm{O}_{5}{ }^{-}$ & 162 & $17.48(17.46)$ & $17.48(17.46)$ & $5.92(5.93)$ \\
\hline Starch & $-\mathrm{C}_{6} \mathrm{H}_{10} \mathrm{O}_{5}{ }^{-}$ & 162 & $17.49 .1(17.46)$ & $17.49(17.46)$ & $5.91(5.93)$ \\
\hline Hexosans & $-\mathrm{C}_{6} \mathrm{H}_{10} \mathrm{O}_{5}{ }^{-}$ & 162 & $17.49(17.46)$ & $17.49(17.46)$ & $5.90(5.93)$ \\
\hline Pentosans & $-\mathrm{C}_{5} \mathrm{H}_{8} \mathrm{O}_{4^{-}}$ & 132 & $17.78(17.77)$ & $17.78(17.77)$ & $5.78(5.80)$ \\
\hline Lignin-S & $-\mathrm{C}_{11} \mathrm{H}_{10} \mathrm{O}_{3.2^{-}}$ & 193 & $26.93(26.97)$ & $26.94(26.98)$ & $2.89(2.85)$ \\
\hline Lignin-H & $-\mathrm{C}_{10.8} \mathrm{H}_{10} \mathrm{O}_{3.6^{-}}$ & 197 & $25.64(25.65)$ & $25.65(25.66)$ & $3.18(3.16)$ \\
\hline
\end{tabular}


Table 11: Experimental (exp) and calculated (calc) TDC of components of extractives in kJ/g.

\begin{tabular}{|c|c|c|c|c|c|}
\hline Sample & Formula & $\mathbf{M}$ & $-\ddot{A}_{c} U^{0} \exp ($ calc) & $-\ddot{\mathbf{A}}_{c} \mathbf{U}^{0} \exp (\mathrm{calc})$ & $-\ddot{\mathbf{A}}_{\mathbf{f}} \mathbf{H}^{0} \exp$ (calc) \\
\hline $\mathrm{ABA}$ & $\mathrm{C}_{20} \mathrm{H}_{30} \mathrm{O}_{2}$ & 302 & 38.29 (38.30) & 38.34 (38.38) & $1.91(1.90)$ \\
\hline TGP & $\mathrm{C}_{51} \mathrm{H}_{98} \mathrm{O}_{6}$ & 806 & $39.68(39.65)$ & $39.75(39.72)$ & $2.52(2.55)$ \\
\hline TGS & $\mathrm{C}_{57} \mathrm{H}_{110} \mathrm{O}_{6}$ & 890 & $40.36(40.34)$ & $40.43(40.41)$ & $2.43(2.45)$ \\
\hline Average: & & & $39.44 \pm 0.94$ & $39.50 \pm 0.95$ & $2.28 \pm 0.40$ \\
\hline
\end{tabular}

Table 12: Experimental (exp) and calculated (calc) TDC of polyolefins in kJ/g.

\begin{tabular}{|c|c|c|c|c|c|}
\hline Sample & Formula & $\mathbf{M}$ & $-\ddot{A}_{c} U^{0} \exp ($ calc) & $-\ddot{\mathbf{A}}_{c} \mathbf{U}^{0} \exp$ (calc) & $-\ddot{\mathbf{A}}_{\mathrm{f}} \mathbf{H}^{0} \exp ($ calc) \\
\hline PEHD & $-\mathrm{CH}_{2}^{-}$ & 14 & 47.00 (46.91) & $47.08(47.00)$ & $1.44(1.52)$ \\
\hline PELD & $-\mathrm{CH}_{2}^{-}$ & 14 & $46.97(46.91)$ & $47.07(47.00)$ & $1.45(1.52)$ \\
\hline PP & $-\mathrm{C}_{3} \mathrm{H}_{6}-$ & 42 & $46.98(46.90)$ & 47.07 (46.99) & $1.45(1.53)$ \\
\hline \multicolumn{3}{|c|}{$\begin{array}{c}\mathrm{PS} \\
-\mathrm{C}_{8} \mathrm{H}_{8}- \\
104\end{array}$} & $41.09(41.14)$ & $41.14(41.18)$ & $0.12(0.09)$ \\
\hline Average: & & & $45.52 \pm 2.75$ & $45.57 \pm 2.77$ & $1.14 \pm 0.65$ \\
\hline
\end{tabular}

In many cases, the TDC are conveniently expressed in kJ/g successfully used for evaluation of TDC of organic components of (Tables 10-12).

biomass, as well as of some plastics.

As can be seen from Tables 7-12, the calculated TDC are quite close to experimentally characteristics determined using a calorimetric bomb. Thus, the calculation method can be

The results of compositional analysis of biomass samples by standard NREL methods are shown in Table 13.

Table 13: Chemical composition of biomass (wt. part).

\begin{tabular}{|c|c|c|c|c|c|c|}
\hline Biomass & Abbr & Cellulose & ${ }^{*}$ Hemi & Lignin & ${ }^{*}$ Extr & Ash \\
\hline Pine wood & PIW & 0.48 & 0.2 & 0.27 & 0.04 & 0.01 \\
\hline Spruce wood & SPW & 0.47 & 0.22 & 0.27 & 0.03 & 0.01 \\
\hline Poplar wood & POW & 0.46 & 0.26 & 0.24 & 0.02 & 0.02 \\
\hline Bagasse & BAG & 0.38 & 0.33 & 0.2 & 0.03 & 0.06 \\
\hline \multicolumn{3}{|c|}{$\begin{array}{c}\text { Corn stalks } \\
\text { COS } \\
0.37 \\
\end{array}$} & 0.35 & 0.19 & 0.03 & 0.06 \\
\hline Switchgrass & SWG & 0.37 & 0.36 & 0.18 & 0.03 & 0.06 \\
\hline Wheat straw & WHS & 0.36 & 0.37 & 0.19 & 0.02 & 0.06 \\
\hline Cardboard & $\mathrm{CAB}$ & 0.6 & 0.12 & 0.18 & 0.03 & 0.07 \\
\hline Wrapping paper & WRP & 0.73 & 0.07 & 0.05 & 0.03 & 0.12 \\
\hline
\end{tabular}

*Hemi denotes Hemicelluloses; Extr denotes Extractives.

The obtained TDC $\left(Y^{o}{ }_{i}\right)$ of individual components, biopolymers and extractives (Tables $10 \& 11$ ), and their content $\left(w_{i}\right)$ in the biomass (Table 13) were used to evaluate the TDC $\left(Y^{\circ}\right)$ of biomass sample according to additivity rule:

$$
Y^{o}=\Sigma w_{i} Y_{i}^{o}
$$

Besides, the pelletized fuels containing of biomass or composite of biomass and mixed polyolefins (POL) were prepared. The TDC of these fuels were determined experimentally (exp) or calculated using the additivity rule (adr). The results revealed that TDC of solid fuels calculated by equation (5) are confirmed by experimentally obtained characteristics (Tables 14 \& 15). These data evidence on adequacy of the additivity rule to evaluate the TDC of biomass-based solid fuels.

Table 14: TDC of biomass samples in $\mathrm{kJ} / \mathrm{g}$.

\begin{tabular}{|c|c|c|c|}
\hline Biomass & $-\ddot{\mathbf{A}}_{\mathbf{c}} \mathbf{U}^{\mathbf{0}} \exp (\mathbf{a d r})$ & $-\ddot{\mathbf{A}}_{\mathbf{c}} \mathbf{U}^{\mathbf{0}} \exp (\mathbf{a d r})$ & $-\ddot{\mathbf{A}}_{\mathbf{f}} \mathbf{H}^{\mathbf{0}} \exp (\mathbf{a d r})$ \\
\hline PIW & $20.68(20.75)$ & $20.68(20.75)$ & $4.96(4.89)$ \\
\hline SPW & $20.50(20.54)$ & $20.50(20.54)$ & $4.96(4.92)$ \\
\hline POW & $19.57(19.55)$ & $19.58(19.56)$ & $5.04(5.06)$ \\
\hline
\end{tabular}


Academic Journal of Polymer science

\begin{tabular}{|c|c|c|c|}
\hline BAG & $18.82(18.75)$ & $18.83(18.76)$ & $4.82(4.89)$ \\
\hline COS & $18.60(18.68)$ & $18.61(18.69)$ & $5.00(4.92)$ \\
\hline SWG & $18.66(18.60)$ & $18.67(18.60)$ & $4.87(4.94)$ \\
\hline WHS & $18.43(18.46)$ & $18.44(18.47)$ & $4.98(4.95)$ \\
\hline CAB & $18.40(18.38)$ & $18.41(18.39)$ & $4.88(4.90)$ \\
\hline WRP & $16.37(16.44)$ & $16.38(16.45)$ & $5.04(4.97)$ \\
\hline
\end{tabular}

Table 15: TDC of pelletized solid fuels (in $\mathrm{kJ} / \mathrm{g}$ ) and ED (in $\mathrm{GJ} / \mathrm{m}^{3}$ ).

\begin{tabular}{|c|c|c|c|c|}
\hline Sample & $-\ddot{\mathbf{A}}_{\mathbf{c}} \mathbf{U}^{\mathbf{0}} \exp (\mathbf{a d r})$ & $-\ddot{\mathbf{A}}_{\mathbf{c}} \mathbf{U}^{\mathbf{0}} \exp (\mathbf{a d r})$ & $-\ddot{\mathbf{A}}_{\mathbf{f}} \mathbf{H}^{\mathbf{0}} \exp (\mathbf{a d r})$ & $-\mathbf{E D}$ \\
\hline Initial SPW & $20.50(20.54)$ & $20.50(20.54)$ & $4.96(4.92)$ & 5.12 \\
\hline Pellets of SPW & $20.62(20.54)$ & $20.62(20.54)$ & $4.84(4.92)$ & 12.35 \\
\hline Pellets of SPW \& 30\% POL & $28.10(28.03)$ & $28.10(28.05)$ & $3.73(3.78)$ & 19.67 \\
\hline Initial BAG & $18.82(18.75)$ & $18.83(18.76)$ & $4.82(4.89)$ & 3.75 \\
\hline Pellets of BAG & $18.79(18.75)$ & $18.80(18.76)$ & $4.85(4.89)$ & 11.26 \\
\hline Pellets of BAG \& 30\% POL & $26.82(26.77)$ & $26.84(26.80)$ & $3.74(3.76)$ \\
\hline
\end{tabular}

The study of pelletized fuels also showed that the densification of initial biomass does not change the energy and enthalpy of combustion, but increases the density of thermal energy (ED):

$$
E D=\Delta_{c} U^{o} x d
$$

where $\mathrm{d}$ is density of solid fuel $\left(\mathrm{kg} / \mathrm{m}^{3}\right)$
Additive of polyolefins into biomass samples increases the energy and enthalpy of combustion, as well as the energy density of the pelletized fuels (Table 15). As a result, energetic features of biomass-based pellets become comparable with those of fossil coals (Figure 1).

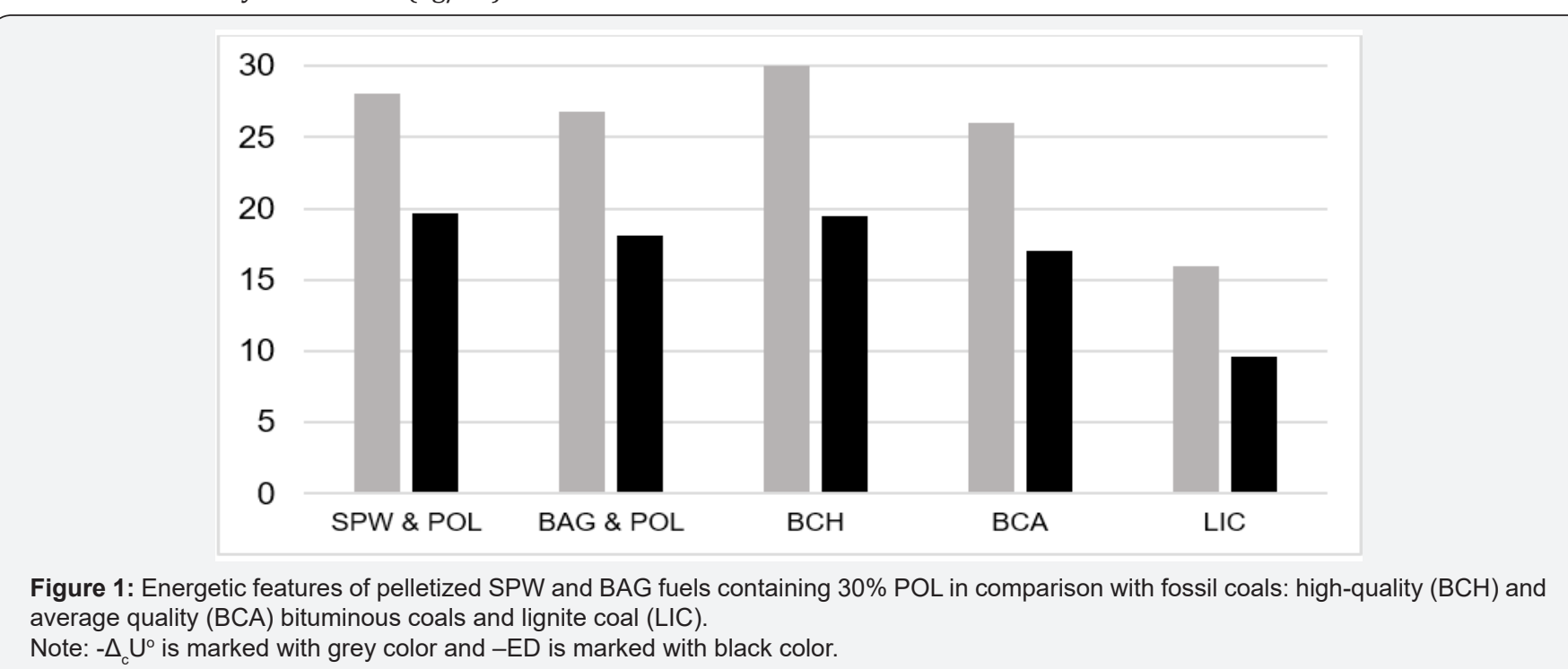

Figure 1 Energetic features of pelletized SPW and BAG fuels containing 30\% POL in comparison with fossil coals: high-quality $(\mathrm{BCH})$ and average quality (BCA) bituminous coals and lignite coal (LIC)

Note: $-\Delta \mathrm{cUo}$ is marked with grey color and -ED is marked with black color

\section{Conclusion}

Solid fuels made of plant biomass and its compositions with plastic additive were studied as an alternative to solid fossil fuels such as coals. For this purpose, experimental and calculation methods were used to determine the thermodynamic characteristics (TDC) of individual components of plant biomass and plastics. Using the results determined for individual components, the TDC of various biomass samples and biomassplastic blends were calculated by means of additivity rule. The results revealed that calculated TDC of solid fuels were close to experimentally obtained values. Thus, the obtained data evidence the adequacy of the additivity rule to evaluate the TDC of solid fuels based on biomass. It has been also found that fuel pellets consisting of plant biomass and additive of plastics are the most promising solid fuels, since they provide the higher energy and enthalpy of combustion, as well as increased density of thermal 
energy than biomass only. Moreover, energetic features of pelletized fuels become comparable with those of fossil coals.

\section{References}

1. Ioelovich M (2013) Plant Biomass as a Renewable Source of Biofuels and Biochemicals. LAP: Saarbrücken: p. 52.

2. Ioelovich M (2015) Recent findings and the energetic potential of plant biomass as a renewable source of biofuels-a review. Bioresources 10(1): 1879-1914.

3. Saidur R, Abdelaziz EA, Demirbas A, Hossain MS, Mekhilef S (2011) A review on biomass as a fuel for boilers. Renew Sust Energy Rev 15(5): 2262-2289.

4. Parikka (2004) Global biomass fuel resources. Biomass and Bioenergy 27: 613-620.

5. Raven PH, Evert RF, Eichhorn SE (2005) Biology of Plants ( $7^{\text {th }}$ edn.). WH Freeman and Company: New York: p. 686.

6. Blankenship RE (2014) Molecular Mechanisms of Photosynthesis (2 ${ }^{\text {nd }}$ edn.). John Wiley \& Sons: Oxford: p. 312.

7. McKendry P (2002) Energy production from biomass: overview of biomass. Biores Technol 83: 37-46.

8. Ioelovich M (2014) Problems of solid biofuels made of plant biomass. Advance in Energy 2(1): 15-20.

9. Barnes DKA, Galgani F, Thompson RC, Barlaz M (2009) Accumulation and fragmentation of plastic debris in global environments. Philos Trans Royal Soc Biological Sci 364: 1985-1998.

10. Uryash VF, Larina VN, Kokurina NY, Novoselova NV (2010) The thermochemical characteristics of cellulose and its mixtures with water Russ JPhys Chem 84(6): 915-921.

11. Günther B, Gebauer K, Barkowski R, Rosenthal M, Bues CT (2012) Calorific value of selected wood species and wood products. Europ J Wood and Wood Prod 70(5): 755-757.

12. Shen I, Zhu S, Liu X, Zhang H, Tan J (2012) Measurement of heating value of rice husk by using oxygen bomb calorimeter with benzoic acid as combustion adjuvant. Energy Procedia 17(Part A): 208-213.

13. Walters RN, Lyon RE, Hackett SM (2000) Heats of combustion of hightemperature polymers. Fire and Mater 24(5): 245-252.
14. Yin C-Y (2011) Prediction of higher heating values of biomass from proximate and ultimate analyses. Fuel 90(3): 1128-1132.

15. Vargas-Moreno JM, Callejón-Ferre AJ, Pérez-Alonso J, Velázquez-Martí B (2012) A review of the mathematical models for predicting the heating value of biomass materials. Renew Sustain Energy Reviews 16(5): 3065-3083.

16. Ioelovich M (2016) Comparison of methods for calculation of combustion heat of biopolymers. American J Appl Sci Eng Tech 1(2): 63-67.

17. White RH (1987) Effect of lignin content and extractives on the higher heating value of wood. Wood and Fiber Sci 19(4): 446-452.

18. Kienzle E, Schrag I, Butterwick R, Opitz B (2001) Calculation of gross energy in pet foods: new data on heat combustion and fibre analysis in a selection of foods for dogs and cats. J Anim Physiol Anim Nutr 85(56): $148-157$

19. Goldberg RN, Schliesser J, Mittal A, Decker SR, Urbas A, et al. (2015) A thermodynamic investigation of the cellulose allomorphs: cellulose (am), cellulose I $\beta(\mathrm{cr})$, cellulose II(cr), and cellulose III(cr). J Chem Thermodyn 81: 184-226.

20. Ioelovich M (2018) Green chemistry and technology of plant biomass. SITA 20(1): 3-12.

21. Sluiter JB, Ruiz RO, Scarlata CJ, Sluiter AD, Templeton DW (2010) Compositional analysis of lignocellulosic feedstocks. Review and description of methods. J Agric Food Chem 58(16): 9043-9053.

22. Ioelovich M, Leykin A (2004) Nano-cellulose and its application. SITA $6(3): 17-24$

23. Jayme G, Knolle H (1964) Introduction into empirical X-ray determination of crystallinity of cellulose materials. Das Papier 18: 249-255.

24. Ioelovich M (2016) Study of thermodynamic stability of various allomorphs of cellulose. J Basic Appl Res Int 16(2): 96-103.

25. Tsiamis DA, Castaldi MJ (2016) Determining Accurate Heating Values of Non-Recycled Plastics. Academy Press: New York: p. 27.

26. Ioelovich M (2017) Calculation of heating value of organic substances using oxygen consumption. J Basic Appl Res Int 21(4): 180-185.

\section{Your next submission with Juniper Publishers} will reach you the below assets

- Quality Editorial service

- Swift Peer Review

- Reprints availability

- E-prints Service

- Manuscript Podcast for convenient understanding

- Global attainment for your research

- Manuscript accessibility in different formats

( Pdf, E-pub, Full Text, Audio)

- Unceasing customer service

Track the below URL for one-step submission

https://juniperpublishers.com/online-submission.php 